\title{
Income and food Engel curves in Rwanda: a household microdata analysis
}

\author{
Aimable Nsabimana ${ }^{1 *}$ (D), Ranjula Bali Swain ${ }^{2,3}$, Yves Surry $^{4}$ and Jean Chrysostome Ngabitsinze ${ }^{5}$
}

\author{
* Correspondence: aimeineza@ \\ gmail.com \\ 'Department of Economics, \\ University of Rwanda, Kigali, \\ Rwanda \\ Full list of author information is \\ available at the end of the article
}

\begin{abstract}
Food insecurity and malnutrition are still major challenges for large proportions of households in Sub-Saharan Africa. The empirical literature on food demand, however, suggests mixed evidence on the roles of income and other socio-economic attributes on food demand. This study analyzes the food demand among households in Rwanda, based on nationally representative household expenditures and demographic (EICV4, 2013/14) survey data. The results show that poor households consume merely food containing higher carbohydrates and starches. Further, the study finds that the majority of rural households spend almost nothing on micronutrients from animal products, suggesting that effective targeted food policy interventions for poor and rural households may play an important role in reducing the incidence of malnutrition through improving food diets.

Keywords: Food Engel curve, Household food demand, Rwanda, Sub-Sahara Africa JEL classification: O55, D12, O18, Q18
\end{abstract}

\section{Springer Open}

\section{Introduction}

Modeling consumer demand has been one of the most momentous trends in the consumer theory literature over the last couple of decades. Both theory and empirical approaches of demand functions have been instrumental in defining developmental and welfare policies. Among others, the Engel curve is regarded as a powerful tool to understand consumer behavior and household welfare in general. In this context, a number of functional forms and estimation techniques for Engel curves have been proposed and applied, including Pollak and Wales (1980), Behrman and Deolalikar (1987), Deaton (1988), Lewbel (1991), Hausman et al. (1995), and You (2003). Engel curves have been applied in the context of developing and developed countries to analyze household expenditure behavior. For instance, Banks et al. (1997) used the model to analyze indirect tax policy reform and the household income distribution in the United Kingdom (UK). On the other hand, Kedir and Girma (2007) estimated Engel curves of urban household food expenditures by accounting for measurement errors in total expenditures in the context of Ethiopia. In this study, non-linear Engel curves have been estimated both parametrically and non-parametrically, for food expenditure patterns between rural and urban households. We analyze separately parametric estimates of

(c) The Author(s). 2020 Open Access This article is licensed under a Creative Commons Attribution 4.0 International License, which permits use, sharing, adaptation, distribution and reproduction in any medium or format, as long as you give appropriate credit to the original author(s) and the source, provide a link to the Creative Commons licence, and indicate if changes were made. The images or other third party material in this article are included in the article's Creative Commons licence, unless indicated otherwise in a credit line to the material. If material is not included in the article's Creative Commons licence and your intended use is not permitted by statutory regulation or exceeds the permitted use, you will need to obtain permission directly from the copyright holder. To view a copy of this licence, visit http://creativecommons.org/licenses/by/4.0/. 
food Engel curve (FEC) expenditures for rural and urban households in the context of developing countries, with a focus on Rwanda. This is because, in low- and middleincome countries, there are still large numbers of rural households where for instance Asia and Africa account for 40 and $48 \%$ of rural households, respectively. Particularly, in some African regions such as East Africa, the proportion of rural households is still more than $70 \%$ (UN-Habitat, 2014). Having such massive proportions of rural households implies that the majority of the population depends on subsistence farming. Henceforth, it can be argued that household location (either rural or urban dwellers) can be considered as an influential factor to affect food expenditure decisions.

\section{Context of food consumption and policies}

Food insecurity and malnutrition are thought by many analysts and policy makers to be important and widespread issues in developing countries, especially in Sub-Sahara Africa (SSA). For instance, the Food and Agricultural Organization (FAO) reported in 2017 that SSA is one of the regions in the world with the largest number (233 millions) of hungry people. In fact, the World Bank (2012) showed that over $47 \%$ of the total population in SSA lived on $\$ 1.90$ a day or less, a driving factor in causing widespread hunger in the region, and in SSA one person out of four is undernourished. Much of the high malnutrition prevalence has been attributed to low household income to meet the required minimum calories and nutrients levels, hence chronic poverty (Melo et al. 2015). The key issue is to know whether a supposed income increase would necessarily be translated into higher food consumption and eventually lead to balanced food diets. Further, rapid urbanization has also been considered as a key contributing factor that affects household food consumption patterns in Africa (Fabiosa 2011).

As far as Rwanda is concerned, despite the 1994 genocide, the country has experienced stunning agricultural and economic growth (where the average of national gross domestic product (GDP) per capita grows at an annual rate of 5\%) coupled with significant progress in social development indicators, such as education, health services, infrastructure development, and poverty reduction. According to the Comprehensive Food Security and Vulnerability Analysis (CFSVA) survey report (World Food Program (WFP) 2016), these remarkable social gains have put Rwanda among the countries that have achieved most of the Millennium Development Goals (MDG). Despite such an impressive progress, poverty remains a huge challenge among Rwandan households. According to the World Bank (2014), the poverty rate in 2014 was 39\% among Rwandan households. Further, there are still a significant number of households that are more vulnerable to high food prices-especially during the lean season when their own stocks have run dry. Those poor households, furthermore, do not have any monetary buffer to protect themselves from the consequences of natural exogenous shocks such as drought, flooding, illness, or crop disease. In this respect, the nutritional value of household food consumption is low among a significant number of households. Among Rwandan households, $45 \%$ is food insecure and some of them can hardly afford to consume protein-rich food items such as meat, milk, or eggs. Although the high prevalence of food-insecure households is typically observed in rural areas, where most families depend mainly on subsistence, there are also important shares of poor urban dwellers that cannot afford to purchase sufficient food, hence becoming food insecure. It is also noteworthy to mention that the economic progress of Rwanda has induced households 
to depend substantially on markets for food consumption and this has been the case for both rural and urban households. For instance, the National Institute of Statistics for Rwanda (NISR) (2016) reported that 70\% of food consumed by Rwandan households is purchased.

The main objective of this study is to shed light on these issues by examining food expenditure elasticities and derive plausible distributions from various household income levels in Rwanda. Based on Working's model (Working 1943), this paper tests the hypothesis that the food budget share and household expenditure elasticities differ between households across location and income levels. Specifically, this paper addresses the following two questions: How do changes in household income affect food consumption behavior in Rwanda? Is there any potential impact of urbanization on food consumption trends in the country? The extent to which households allocate their income between food and non-food items however depends on household location, market prices, and income opportunities (Barrett et al. 2001). Hence, this paper seeks to provide additional evidence of the potential mechanisms driving food consumption patterns in Rwanda.

In order to achieve this, we estimate non-linear FECs that provide useful insights in many aspects of consumer behavior with policy implications (Almås 2012; Kedir and Girma 2007). We employ the fourth round Integrated Household Living Conditions Survey of Rwanda (EICV4), conducted in 2013/14 by NISR to derive Engel curves for groups of food products. The findings exhibit concave Engel curves for cereals, and roots and tubers, while the remaining food categories are characterized by U-shaped relationships between food budget shares (vegetables, meat products, beverages and other food items) and household food expenditures. The results further reveal that unconditional expenditure elasticities tend to be relatively higher for rural than for urban households, an indication that in Rwanda, the rural areas tend to have poorer and more food-insecure households than urban areas. That is, as total expenditure increases rural households spend proportionally more on food than urban households, especially on low-value staples, starches, and cereal products. The findings confirm the results in earlier studies where low-income households spend a greater portion of their budget on food (Muhammad et al. 2011).

The contribution of the present study to the literature is twofold. First, unlike earlier studies that investigate FECs in developing countries (Abdulai and Aubert 2004; Kedir and Girma 2007; Abdulai and Christian 2011; Hasan 2016; Melo et al. 2015; Moss et al. 2016), the present study considers household location as a key potential driving force in food consumption patterns. As it has been documented in the existing literature, SSA countries, including Rwanda, have experienced excessive urbanization since the late 1990s and have faced a daunting set of challenges that include a deficient capacity of service provisions and enormous gaps in food market prices between urban and rural areas (Maxwell 1999). For instance, the population in urban areas in SSA has increased from 203 million in 1990 to 401 million in 2010 (UN-Habitat (United Nations Human Settlements Programme) 2014). This excessive urban growth rate in the region has further exacerbated urban food insecurity and poverty. It is also important to note that food demand in urban areas depends enormously on household income capacity (Smit 2016), and this has induced unrestrained pressure on urban dwellers who may have limited income opportunities and end up falling short on food consumption. In 
addition, the excessive urban growth rate puts pressure on rural households who need not only to produce for their own consumption, but also for non-farm households living in urban areas; hence, this could potentially lead to inflated food prices. Therefore, carrying out this study, while identifying food consumption patterns between urban and rural households in Rwanda, provides an opportunity for policy interventions to clearly understand distinctive attributes of rural and urban consumption trends. More importantly, Rwandan household expenditures show high levels of extreme observations. To deal with this issue and reduce the weight put on extreme observations, we estimated quantile regressions, and M-robust estimator models that account effectively for long-tail distributions among household expenditures.

Second, we examine the nonlinearity of Engel curves of different food categories and how these food categories respond to household incomes. Hasan (2016) examined Engel curves for major expenditure categories in Bangladesh with attention to the functional form of the Engel curves. However, there is scant literature on FECs in an African context that accounts for income (Kedir and Girma 2007). Therefore, this paper attempts to fill this gap in the literature. In terms of policy relevance, this paper is useful-especially in developing countries like Rwanda with emerging and intense urbanization, and income and population growth-to reveal the impact of household location on food demand patterns and the possible policy interventions on food security and malnutrition. Fabiosa (2011) showed that there are important differences in dietary compositions and food supply structures across household locations in SSA. Hence, a good understanding of rural and urban food consumption patterns will provide more insights on purposive and targeted food policies.

The rest of the paper is organized as follows. The next section develops the empirical strategy and identification approach used in the study. The "Data" section describes the data. Both household demographics and characterization of household expenditures are formally explained in this section. The results and discussion of findings are reported in the fifth section. The last section concludes with a discussion of potential policy implications derived from our empirical results.

\section{Identification strategy and empirical approach}

This study estimates FECs which are a powerful tool to understand consumer behavior and household welfare (Cirera and Masset 2010). The FEC plays an important role to describe food consumption patterns in households' response to income shocks. We use household survey data to derive FECs of different groups of food products. An important aspect of using such household survey data is that the data on household expenditures are more reliable than income, especially in the case of low-income and agricultural economies (Deaton 1997; Engel and Kneip 1996; Hasan and Mozumder 2017). Therefore, most studies rely on household expenditure instead of income in modeling FECs. In this article, the dependent variables are expressed in terms of shares in household total food expenditure on each of six food groups (cereals, roots and tubers, vegetables, meat products, beverages, and other food items), and this allows to capture a range of functional forms. ${ }^{1}$ The category "other food items" contains the rest of all other food expenses by the households that are not part of the first five ones.

${ }^{1}$ Note that consumption and expenditure in this text are used interchangeably. 
To estimate the quadratic Engel curves of all food groups, two critical estimation issues have been accounted for: variable measurement errors and the presence of extreme values (outliers) in household expenditures. In developing countries, most of the household consumption and expenditures information are taken from household surveys. Household self-reported expenditures, however, are usually marred with measurement errors due to recalling difficulties, including fading of people's memories or reporting errors associated with respondents being overwhelmed by the length of the survey or by the number of items covered (Grosh and Glewwe 2000). Errors can also be caused by misreporting during data collection. We follow Hausman et al. (1995) to deal with measurement errors in household expenditure data. The issue of extreme values in household survey data is very common, especially for household income and expenditure variables, where households may have divergent income categories, hence, resulting in high levels of variance in the data. To deal with this issue, we follow a similar approach as You (2003) to estimate robust estimation models of Engel curves.

However, it has also been shown that Engel curve models often suffer from an endogeneity bias when the food budget shares are regressed on total household expenditures (Hausman et al. 1995). More specifically, a simultaneous decision on using household expenditure together with an allocation on each food group can lead the former to be endogenous. One of the best solutions to overcome this problem is to use an instrumental variable (IV) estimation approach. The major challenge is, however, to get good instruments. In the present article, we follow the IV approach suggested by Hausman et al. (1995) and use household income as instrument for total expenditure. A similar procedure has been used in the literature in numerous Engel curve studies (Banks et al. 1997; Blundell et al. 1998; Blundell et al. 2007; Hasan and Mozumder 2017). According to Hausman et al. (1995), the main reason to use income as IV for household expenditures is that the two are highly correlated and in a twostage budgeting process, household income does not have a direct effect on expenditure shares, an indication of a valid instrument. For identification purposes, with censored expenditures and heterogeneity between rural and urban households, both standard and robust estimation techniques have been applied. In this context, besides the use of an IV estimation approach, the IV-tobit and the MM-estimator (Yohai 1987) are also employed.

The estimated Engel curves and food expenditure elasticities, both for rural and urban households, are intended to capture empirical food consumption patterns in Rwanda. To derive household food expenditure elasticities, we assume a two-stage budgeting procedure as shown in Fig. 1. In the first budgeting stage, households determine the shares of income that are devoted to food and non-food items and we model food and non-food budget shares on the logarithm of total household expenditures. In the second budgeting stage, households decide to allocate food expenditures across the six different food groups and we model these food budget shares on the logarithm of total household food expenditures. In the first budgeting stage, we derive expenditure elasticities of food, while in the second stage conditional and unconditional elasticities of all food groups are estimated. To derive consistent standard errors of unconditional expenditure elasticities for each food group, we opt for a delta method approach (Greene 2008). In estimating the Engel curves, we essentially build on a standard budget share model borrowed from Working (1943) and Leser (1963) to define the following quadratic relationship. ${ }^{2}$

${ }^{2}$ This relationship is also commonly called the Working-Leser (W-L) model. 




Fig. 1 Household two-stage budgeting approach for food demand in Rwanda

$$
w_{i h}=\alpha_{1}+\alpha_{2} \log \left(y_{h}\right)+\alpha_{3}\left[\log \left(y_{h}\right)\right]^{2}+\sum_{k=1}^{N} \beta_{i k} D_{k h}+u_{i h}
$$

for household $h=1 \ldots \ldots . H$ and $i=1 \ldots \ldots .6$ food groups. $w_{i h}$ represents a particular household's budget share for food group $i, y_{h}$ designates total food expenditures of household $h$, and $D_{k}$ represents the vector of demographics and household characteristics as defined in Table $1 ; \alpha_{1}, \alpha_{2}, \alpha_{3}$, and $\beta_{i k}$ 's are parameters to estimate: and "log" designates natural logarithm. The term $u_{i h}$ is the stochastic disturbance of the model with mean zero. From Eq. (1), the expenditure elasticities of food demand $\left(\widehat{\eta_{i h}}\right)$ by household $h$ can be derived as follows:

$$
\widehat{\eta_{i h}}=1+\frac{\widehat{\alpha_{2}}}{\widehat{w_{i h}}}+\frac{2 \widehat{\alpha_{3}} \log \left(y_{h}\right)}{\widehat{w_{i h}}}
$$

where $\widehat{\alpha_{2}}$ and $\widehat{\alpha_{3}}$ are the estimated parameters of the above Working-Leser (W-L) model; and $\widehat{w_{i h}}$ is the estimated budget share of food group $i$ by household $h$.

\section{Data}

Household expenditures, demographics, and characteristics of households used in this study are extracted from the fourth Integrated Household Living Conditions Survey of Rwanda (EICV4) conducted in $2013 / 2014$ by NISR. A sample of 14,172 households is used, comprising 11,660 rural and 2512 urban households, representing $82.2 \%$ and 17.8 $\%$ of the total sample, respectively. The data covers the entire country including its four provinces and the city of Kigali. The Southern province accounts for 27\%, Eastern consists of $24 \%$, Western has $23 \%$, the Northern Province accounts for $16 \%$, and the city of 
Table 1 Distribution of demographic and household characteristics in the study

\begin{tabular}{|c|c|c|c|c|}
\hline \multirow[t]{2}{*}{ Variables } & \multicolumn{2}{|c|}{ Rural households } & \multicolumn{2}{|c|}{ Urban households } \\
\hline & mean & std. dev. & mean & std. dev. \\
\hline \multicolumn{5}{|l|}{ Demographics } \\
\hline Average age of household head $(\mathrm{HH})$ & 45.86 & 16.14 & 41.08 & 14.31 \\
\hline Household size (average members per household) & 4.58 & 2.04 & 4.60 & 2.37 \\
\hline Adults in household & 2.42 & 1.08 & 2.71 & 1.38 \\
\hline Children in household & 2.16 & 1.60 & 1.89 & 1.67 \\
\hline Ratio of household members of age less than or equal to 6 years & 0.19 & 0.18 & 0.16 & 0.17 \\
\hline Ratio of household members between 7 and 16 years of age & 0.23 & 0.21 & 0.18 & 0.20 \\
\hline Ratio of household members between $17-59$ years of age & 0.49 & 0.23 & 0.61 & 0.25 \\
\hline Ratio of household members of 60 years of age or more & 0.09 & 0.20 & 0.05 & 0.13 \\
\hline \multicolumn{5}{|l|}{ Education } \\
\hline $\mathrm{HH}$ has no education (dummy $=1,0$ otherwise) & 0.54 & 0.49 & 0.26 & 0.43 \\
\hline $\mathrm{HH}$ has primary education (dummy $=1,0$ otherwise) & 0.41 & 0.49 & 0.41 & 0.49 \\
\hline $\mathrm{HH}$ has secondary education (dummy $=1,0$ otherwise) & 0.04 & 0.20 & 0.20 & 0.39 \\
\hline $\mathrm{HH}$ has university level (dummy = 1, 0 otherwise) & 0.01 & 0.09 & 0.13 & 0.33 \\
\hline Spouse with no education (dummy $=1,0$ otherwise) & 0.65 & 0.47 & 0.53 & 0.49 \\
\hline Spouse with primary education (dummy $=1,0$ otherwise) & 0.31 & 0.46 & 0.26 & 0.43 \\
\hline Spouse with secondary education (dummy $=1$; 0 otherwise) & 0.03 & 0.17 & 0.15 & 0.35 \\
\hline Spouse with university level (dummy $=1 ; 0$ otherwise) & 0.01 & 0.05 & 0.06 & 0.25 \\
\hline \multicolumn{5}{|l|}{ Location } \\
\hline Southern Province(dummy = 1, 0 otherwise) & 0.30 & 0.45 & 0.12 & 0.33 \\
\hline Western Province(dummy = 1, 0 otherwise) & 0.24 & 0.43 & 0.17 & 0.37 \\
\hline Eastern Province(dummy = 1; 0 otherwise) & 0.26 & 0.44 & 0.10 & 0.30 \\
\hline Northern Province(dummy = 1, 0 otherwise) & 0.18 & 0.38 & 0.07 & 0.26 \\
\hline Kigali City (dummy = 1, 0 otherwise) & 0.00 & 000 & 0.51 & $0.49^{\mathrm{a}}$ \\
\hline \multicolumn{5}{|l|}{ Other household characteristics } \\
\hline Household with non-farm business (dummy = 1, 0 otherwise) & 0.47 & 0.49 & 0.74 & 0.43 \\
\hline $\mathrm{HH}$ is monogamous (dummy = 1,0 otherwise) & 0.61 & 0.48 & 0.59 & 0.49 \\
\hline Number of sampled households & 11,660 & & 2512 & \\
\hline
\end{tabular}

${ }^{\mathrm{a}}$ All households located in Kigali are considered to be urban dwellers and for this reason are part of the urban household category. $H H$ Household Head

Kigali represents $10 \%$ of the total sampled households. Table 1 provides descriptive statistics of the variables used in the study. To account for the effects of differences in household composition, we use demographic and household-specific variables, i.e., the age of the household head $(\mathrm{HH})$; household size; number of adult members in the household; education level of both $\mathrm{HH}$ and spouse; ratios of household members of age below 6 , between 7 and 16, between 17 and 59, and 60 or more; a dummy of whether the household has a non-farm business or not; and finally we also have a dummy that defines monogamous households. The selection of these variables is linked to their potential influence on household preferences and food expenditure decisions. For instance, having children might induce the household to buy dairy products (Boysen 2016). The HH is assumed to have a leading control over the household resources and more importantly over household budget allocations. The age of the $\mathrm{HH}$ accounts for cohort-related and gender preferences. In addition, it has been shown that household 
expenditure is an increasing function of family size and the number of adults in the household (Lewbel 2006). In this respect, we could say that as the number of family members increases, the chance to spend more on food increases. For this reason, it is necessary to determine the level at which family size influences household food consumption.

EICV4 provides information on household expenditures for both food and non-food items. Table 2 presents key indicators (quartiles, median, and mean) of the distribution of household expenditures for food and non-food items by rural and urban households in Rwanda. An examination of the figures presented in Table 2 indicates that there are significant discrepancies in annual expenditures between rural and urban households. Based on the first quartile, a household spends 416,284 Rwandan francs in rural areas while the same figure for urban dwellers amounts to 868,274 Rwandan francs. While the median (second quartile) indicates that family income is $72 \%$ higher for urban than for rural households and the mean values show that urban households may earn $78 \%$ more than their rural counterparts, these are indications that we need to analyze separately concerning consumption patterns.

Note that when computing total annual household expenditures, the values of the household's own production were also accounted for. Quantitative information on the second stage of the household budgeting process is shown in the lower part of Table 2, where the expenditure shares of all food groups across various income categories are provided. The most interesting observation is that the majority of Rwandan households, especially in rural areas, spend most of their food expenditures on cereals, and roots and tubers. More specifically, Table 2 indicates that poor people in rural areas spend

Table 2 Distribution of rural and urban household expenditures and of food group expenditure shares

\begin{tabular}{|c|c|c|c|c|c|c|c|c|}
\hline & \multicolumn{4}{|c|}{ Rural households } & \multicolumn{4}{|c|}{ Urban households } \\
\hline & \multicolumn{3}{|c|}{ Quantiles } & \multirow[t]{2}{*}{ Mean } & \multicolumn{3}{|c|}{ Quantiles } & \multirow[t]{2}{*}{ Mean } \\
\hline & q25 & q50 & q75 & & $\mathrm{q} 25$ & $\mathrm{q} 50$ & q75 & \\
\hline \multicolumn{9}{|l|}{ Total Expenditures } \\
\hline $\begin{array}{l}\text { Annual household expenditures. } \\
\text { (Frw) }\end{array}$ & $\begin{array}{l}416 \\
284\end{array}$ & $\begin{array}{l}643 \\
431\end{array}$ & $\begin{array}{l}1,000 \\
973\end{array}$ & $\begin{array}{l}833 \\
281\end{array}$ & $\begin{array}{l}868 \\
274\end{array}$ & $\begin{array}{l}1,638 \\
287\end{array}$ & $\begin{array}{l}3,253 \\
654\end{array}$ & $\begin{array}{l}3,072 \\
913\end{array}$ \\
\hline $\begin{array}{l}\text { Annual household expenditures } \\
\text { (USD) }\end{array}$ & 623 & 963 & 1498 & 1247 & 1299 & 2452 & 4870 & 4600 \\
\hline $\begin{array}{l}\text { Total food total expenditures } \\
\text { (Frw) }\end{array}$ & $\begin{array}{l}140 \\
311\end{array}$ & $\begin{array}{l}268 \\
706\end{array}$ & 520,716 & $\begin{array}{l}286 \\
760\end{array}$ & $\begin{array}{l}136 \\
542\end{array}$ & 272,140 & $\begin{array}{l}1,045 \\
872\end{array}$ & 768,005 \\
\hline Total non-food expenditure (Frw) & $\begin{array}{l}260 \\
085\end{array}$ & $\begin{array}{l}485 \\
340\end{array}$ & $\begin{array}{l}1,040 \\
375\end{array}$ & $\begin{array}{l}546 \\
520\end{array}$ & $\begin{array}{l}573 \\
323\end{array}$ & 809,710 & $\begin{array}{l}3,103 \\
371\end{array}$ & $\begin{array}{l}2,304 \\
907\end{array}$ \\
\hline \multicolumn{9}{|l|}{ Expenditure share of food groups } \\
\hline Cereals & 0.36 & 0.37 & 0.37 & 0.36 & 0.27 & 0.28 & 0.24 & 0.25 \\
\hline Roots and tubers & 0.36 & 0.35 & 0.32 & 0.35 & 0.22 & 0.21 & 0.13 & 0.16 \\
\hline Vegetables & 0.13 & 0.11 & 0.10 & 0.12 & 0.24 & 0.20 & 0.18 & 0.19 \\
\hline Meat products & 0.02 & 0.03 & 0.04 & 0.03 & 0.04 & 0.06 & 0.09 & 0.07 \\
\hline Beverages & 0.03 & 0.04 & 0.05 & 0.04 & 0.03 & 0.04 & 0.06 & 0.05 \\
\hline Other food items & 0.10 & 0.10 & 0.12 & 0.10 & 0.20 & 0.21 & 0.30 & 0.27 \\
\hline
\end{tabular}

Household expenditures are reported both in Rwandan Francs (Frw) and US dollars. The exchange rate used is the average exchange rate prevailing during the period (October 2013-October 2014) which is the period the EICV4 survey was undertaken. The exchange rate used is $1 \$$ US $=668$ Frw. Source: Authors computations based on Rwandan EICV4, 2013/2014 data 
more than $72 \%$ of their income on cereals and roots, signaling that starch and carbohydrate food products are the major components of their meals. Another interesting observation from Table 2 is that Rwandan households, both rural and urban, spend insignificant amounts on protein food products such as meat products.

\section{Results: presentation and discussion}

We start the results discussion by performing conditional quantile regressions by examining the relationship between household expenditure shares of food and non-food and the logarithm of total household expenditures. The plot of the estimated coefficients obtained for different quantiles in Fig. 2a reveals that all are negative regardless of quantiles. As these estimated coefficients represent the marginal response (semi-elasticity $^{3}$ ) of the food budget share with respect to the log of total household expenditures, it implies that the underlying Engel curve for food in Rwanda is characterized by an inverse relationship between food budget shares and total food expenditures. Turning now to Fig. 2b, all the estimated marginal responses (semi-elasticities) obtained for different levels of quantiles are positive, thus indicating that non-food expenditure shares increase as total household expenditures rise. This pattern is expected as households with higher incomes reduce their expenditures devoted to food and increase non-food expenditures.

In the next stage, we derive nonparametric localized polynomial estimates on both food and non-food household expenditures. Fig. 3a and b exhibit relationships between food and non-food budget shares with total household expenditures, respectively. The food budget share, presented in Fig. 3a, indicates a negative association with total household expenditure, while Fig. $3 \mathrm{~b}$ shows a positive association with total household consumption. From both sides, Engel's law is consistently fulfilled in the sense that the proportions of food and non-food expenditure decline/increase respectively as households' income rises. ${ }^{4}$

In the second lower stage, we estimate various nonparametric Engel curves for each food category. A localized polynomial of second degree with a $95 \%$ confidence interval is estimated for all food groups and the results are presented in Fig. 4. The quadratic relationship between each food group budget share and total food expenditure is remarkably pronounced for most of the food groups. Specifically, the findings exhibit concave Engel curves for cereals, and roots and tubers, while other food categories are characterized by U-shaped relationships between their budget shares (vegetables, meat products, beverages, and other food) and total household food expenditures. As discussed previously by Kedir and Girma (2007), the use of such nonparametric regressions provides the best alternative to least squares as they allow data to choose local shapes of conditional relationships. The Engel curves of cereals, and roots and tubers represent both normal good and inferior good segments. At lower income levels, an average lower income household would like to spend more on these latter food

${ }^{3}$ Due to the functional form adopted for these conditional quantile regressions, the estimated (quantilerelated) coefficients $\beta(q)$ associated with the explanatory variable (log of total household expenditures) are

formally defined as follows: $\frac{\partial \text { budget share }(q)}{\partial \log (\text { total household expenditure) }}=\beta(q)$, where food and non-food budget shares and the coefficients $\beta(q)$ vary with each quantile $(q)$.

${ }^{4}$ All these findings derived from Fig. $3 \mathrm{a}$ and $\mathrm{b}$ are in line with and confirm the analysis conducted with the conditional quantile regressions. 


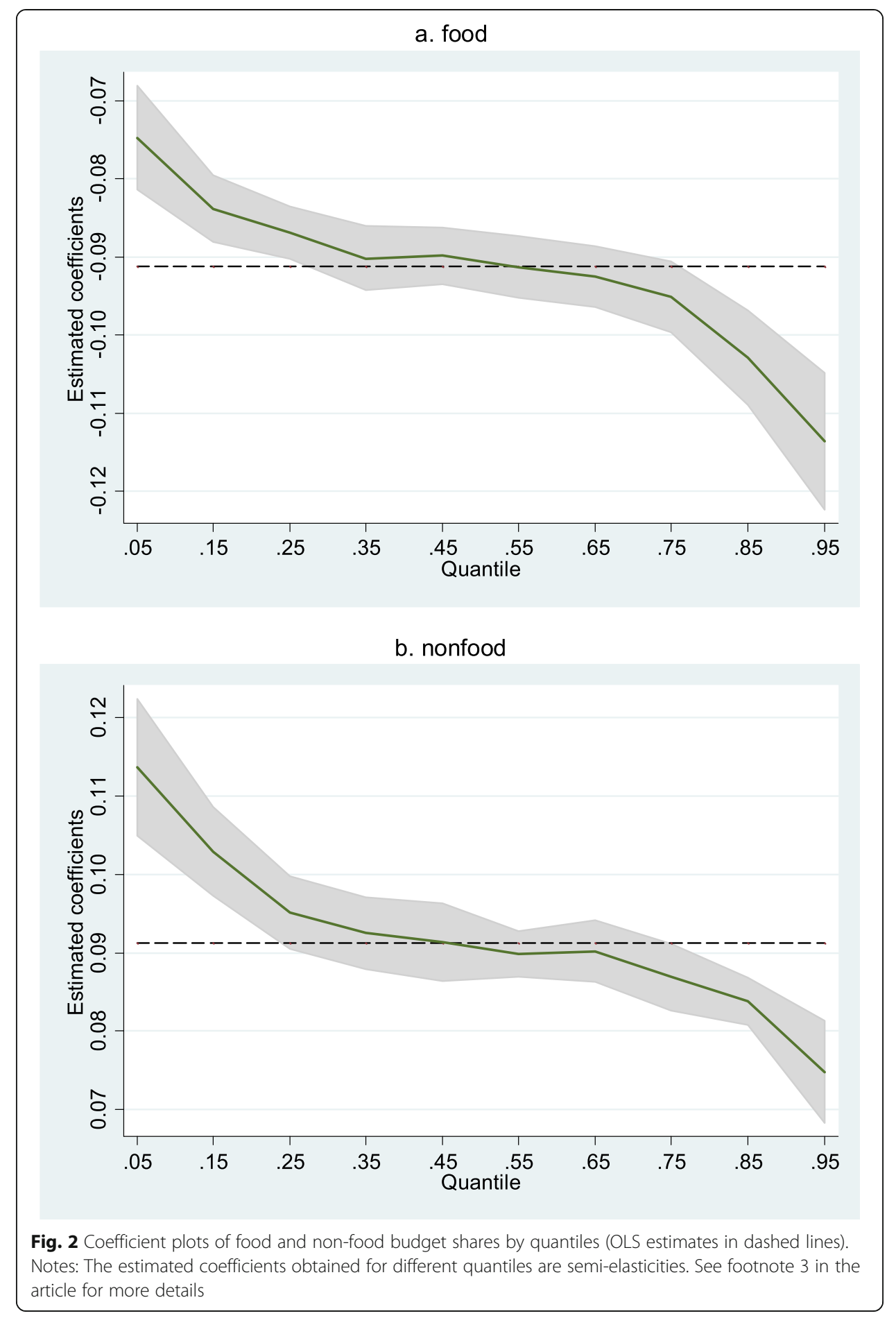

products as their income increases, but eventually, when household income reaches a certain threshold level, cereals and roots and tubers become inferior goods for those households. This has been confirmed in the literature (Lewbel 1991, 2006). In this respect, it is evident to say that the left-hand side of maximum points of Fig. 4a and b represents normal goods for those households, while the right-hand side of the same 


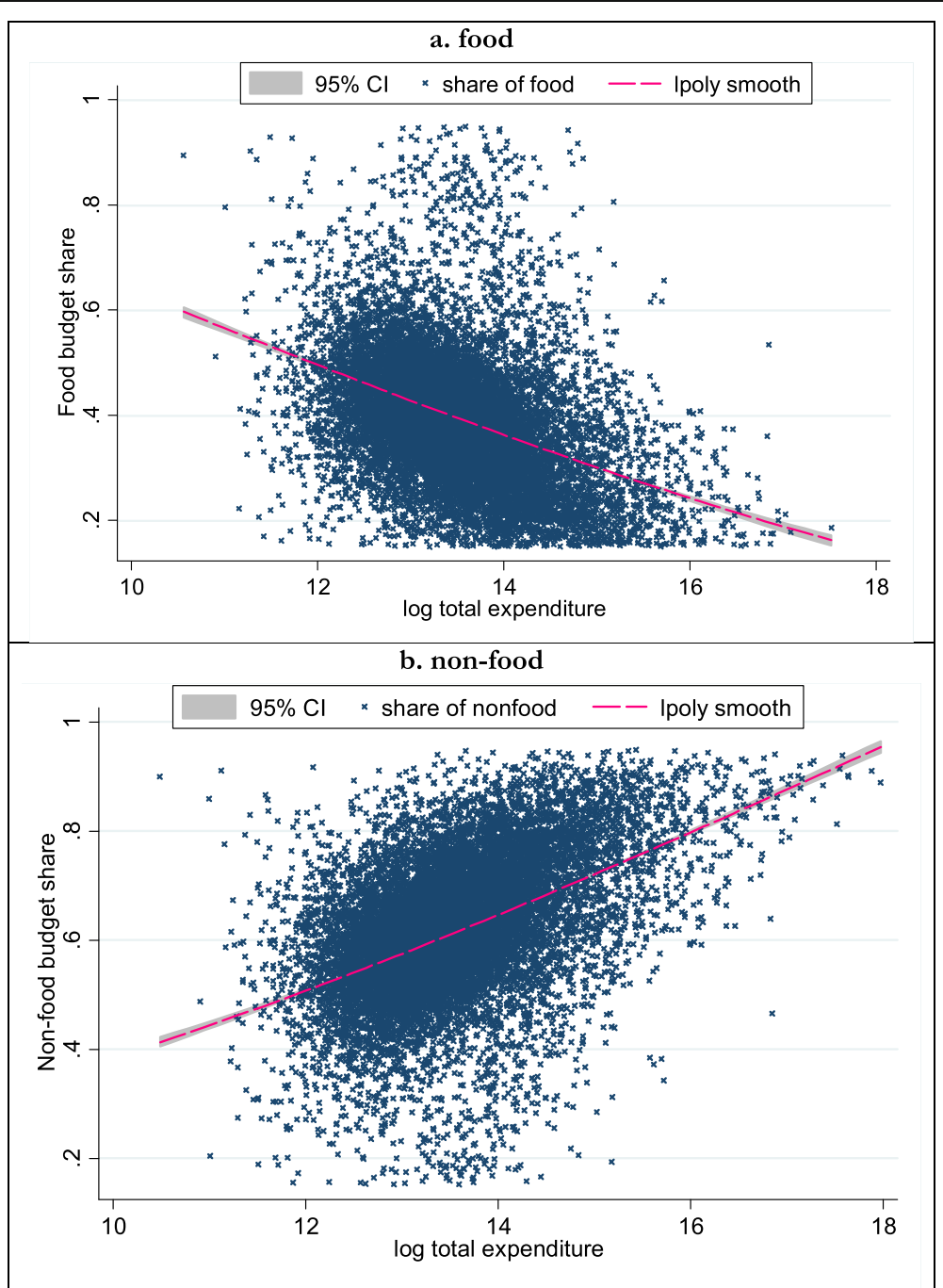

Fig. 3 Estimated Engel curves for food and non-food products in Rwanda. Notes: The estimated Engel curves have been obtained using a nonparametric approach based on the use of local quadratic polynomials. 95\% Cl, 95\% confidence interval; "Ipoly smooth", smooth localized polynomials

curves indicates inferior goods for households. Conversely, the Engel curves of vegetables, meat products, beverages, and other food exhibit both inferior and normal good segments. In this case, in Fig. 4c-f at lower income levels, an average poor household would like to spend relatively less on these latter food groups as their income increases, but eventually, when household income reaches a certain threshold level at lowest vertex points in Fig. 4c-f, vegetables, meat products, beverages, and the other food group become normal goods for households. The estimated FECs for rural and urban households are presented in Additional file 1: S1 and Figure S2, respectively.

Furthermore, we also derive the expenditure elasticities by assuming separable preferences from the assumed two-stage household budgeting process. The estimates of W-L models (Eq. 1) of food demand are reported in Table 3. We derive urban and rural household estimates separately to capture consumption differences between rural and urban dwellers. Interestingly, the results indicate that food budget shares exhibit a 

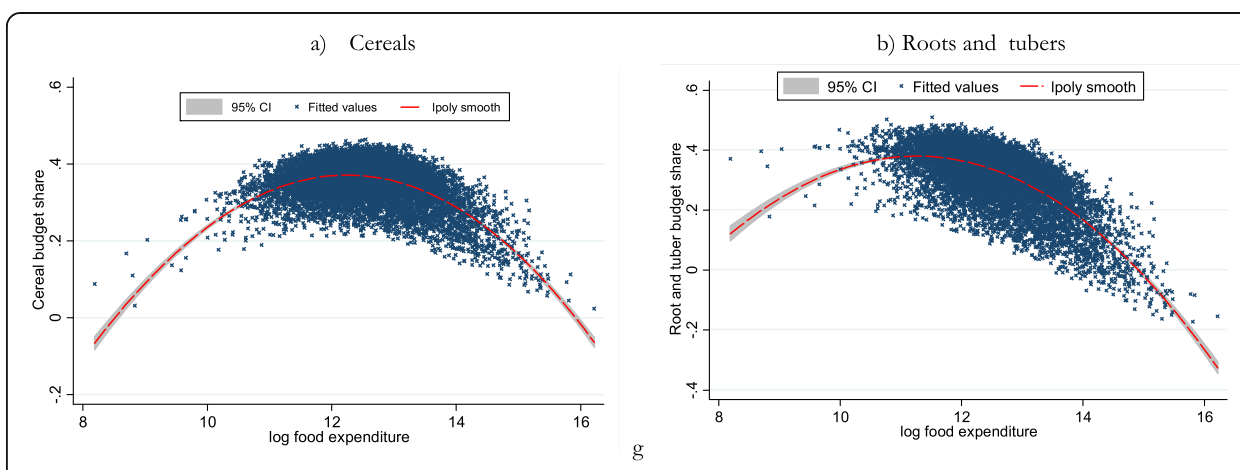

c) Vegetables
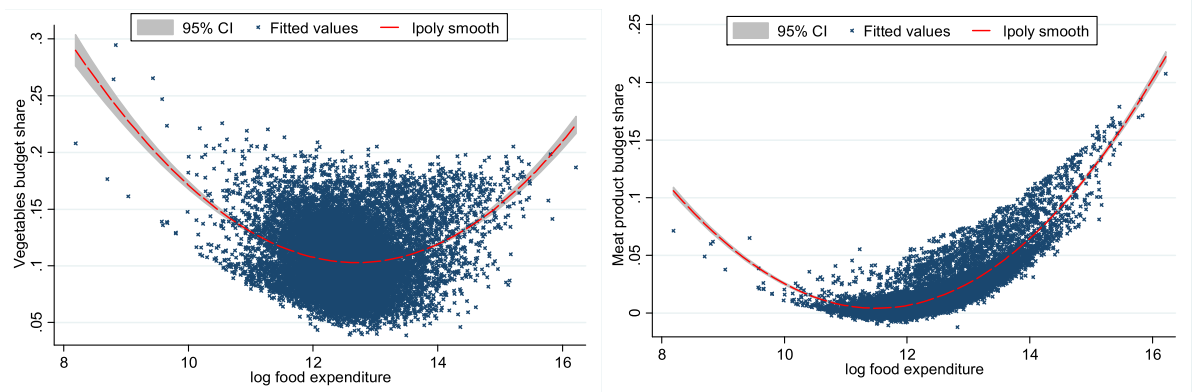

e) Beverages
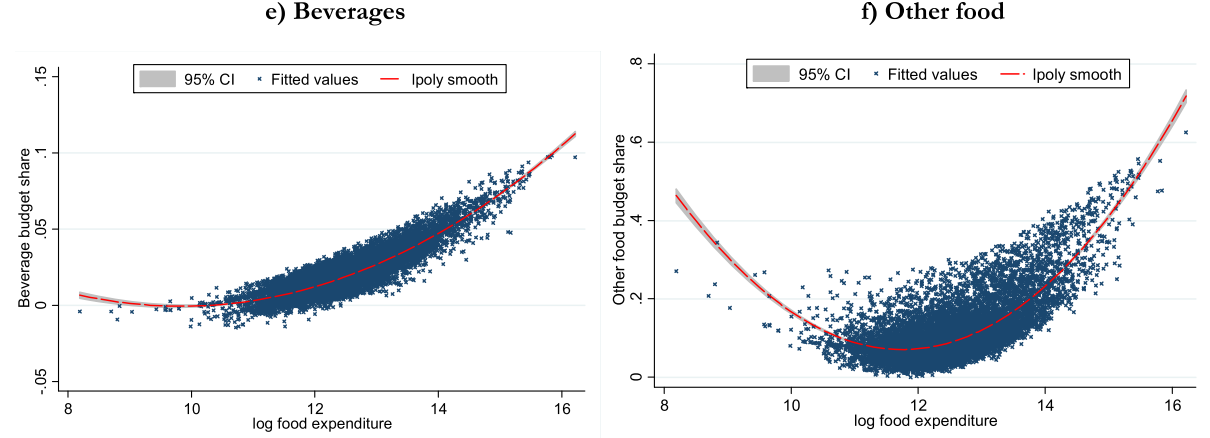

Fig. 4 Estimated Engel curves for different groups of food products in Rwanda. Notes: The estimated Engel curves have been obtained using a nonparametric approach based on the use of local quadratic polynomials. 95\% Cl, 95\% confidence interval; "Ipoly smooth", smooth localized polynomials

concave relationship with total household expenditures while an opposite pattern is occurring for urban dwellers where the budget food share is a convex (inverse U-shaped), albeit not significant, function of the total expenditures. First, for rural areas, the observed food demand patterns are plausible for poor countries with households that may have unmet demands for necessary goods (including food, education, and housing) at low-income levels. This implies that as household incomes rise, they spend their additional earnings on those necessary goods more than proportionally and this induces a reduction in budget shares of other types of household expenditures (Hasan 2016). When household incomes increase enough and reach a certain threshold level, they can decide to spend more than proportionally on other categories of goods and services (e.g., energy, electronical appliances such as refrigerators). For urban households, the results reveal a negative association for total household expenditure and a positive 
relationship with its square. This shows that there is a U-shaped relationship of food budget share with total household expenditures although it is not significantly different from zero. Hence, the study reveals a quadratic FEC in both rural and urban food demand patterns.

In the lower part of Table 3, we provide the turning point of the underlying quadratic Engel curves for rural and urban household food consumption. For rural households, the turning point of the quadratic Engel curve is estimated at 200,138 Rwandan Francs (Frw). This value is equivalent to the $12^{\text {th }}$ percentile of the rural household expenditure data, and this implies that around a tenth of the rural household observations in the FECs are sloping upward ${ }^{5}$. Furthermore, we also provide the turning point from the food FECs for urban household expenditures which is extremely large, and this suggests the presence of outliers in urban household expenditures. Therefore, we believe that the results from rural household expenditures are more reliable than those obtained for urban areas for policy making purposes. In Additional file 1: Tables S2 and S3, we provide the turning points for FECs for all food categories and for rural and urban households. To relate the turning points from household expenditures and poverty level in Rwanda, we only use rural household turning points, as it is believed to be less contaminated by outliers. In rural areas, the turning point was 200,138 Frw and comparing this with the per adult equivalent poverty line (Frw 159,375 per year) from NISR (2018), it is clearly shown that the poverty line is $25.5 \%$ lower than the turning point for rural households. Intuitively, this indicates that, when rural households are considered separately, they seem to have relatively better welfare. Indirectly, this would indicate that among urban households, there might be some households that are much poorer than their rural counterparts.

For robustness checks, we estimate the W-L models for food demand across rural and urban households using MM-estimated and IV-tobit models, and estimates are reported in Additional file 1: Table S3. The results reveal similar trends of the relationship between food budget shares and total household expenditures, hence an indication that our model works well. We derive household food elasticities using Eq. (2), and the results are presented at the bottom of Table 4. The study shows that food income elasticity estimates for rural and urban households were 0.76 and 0.63 , respectively, and this is not surprising.

Other studies, such as Weatherspoon et al. (2017) also find that on average, $65 \%$ of Rwandan household income is spent on food. To test the validity of the instruments, we perform an Anderson likelihood ratio test, the results of which are presented in the lower part of Table 3. The test shows that excluded instruments are not relevant in the sense that they are all correlated with endogenous total household food expenditures.

To make our study useful for policy makers, we estimate W-L models with all food categories across rural and urban households and results are reported in Additional file 1: Tables S4 and S5 for rural and urban households, respectively. The coefficient estimates associated with total household expenditures in all the budget shares equations of all food categories confirm the existence of non-linear Engel curves. In rural areas, some Engel curves associated with cereals, roots and tubers, and vegetables reaffirm the

${ }^{5}$ In this study, unlike in the work by Kedir and Girma (2007), we derive food expenditure elasticities for rural and urban households separately. In addition, we also control for measurement errors associated with the total household expenditure variables in the right-hand side of the estimated W-L models. 
Table 3 Estimated W-L model for food consumption: first upper stage

\begin{tabular}{|c|c|c|}
\hline \multirow[t]{2}{*}{ Explanatory variables } & \multicolumn{2}{|c|}{ Estimated coefficients } \\
\hline & Rural households & Urban households \\
\hline \multirow[t]{2}{*}{ Log(total household expenditure) } & $0.946^{* * *}$ & -0.408 \\
\hline & $(0.215)$ & $(0.533)$ \\
\hline \multirow[t]{2}{*}[\text{Log(totalhouseholdexpenditure)}]{$^{2}$} & $-0.039^{* * *}$ & 0.010 \\
\hline & $(0.008)$ & $(0.018)$ \\
\hline \multirow[t]{2}{*}{ Household size } & $0.012^{* * *}$ & $0.017^{* * *}$ \\
\hline & $(0.001)$ & $(0.002)$ \\
\hline \multirow[t]{2}{*}{ Number of adults } & $-0.008^{* * *}$ & $-0.006^{*}$ \\
\hline & $(0.003)$ & $(0.004)$ \\
\hline \multirow[t]{2}{*}{$\mathrm{HH}$ age } & $0.207^{* * *}$ & -0.001 \\
\hline & $(0.062)$ & $(0.185)$ \\
\hline \multirow[t]{2}{*}{$\mathrm{HH}$ age squared } & $-0.024^{* * *}$ & -0.000 \\
\hline & $(0.008)$ & $(0.025)$ \\
\hline \multirow[t]{2}{*}{ Household with non-farm business } & $-0.014^{* * *}$ & $-0.021^{* * *}$ \\
\hline & $(0.002)$ & $(0.008)$ \\
\hline \multirow[t]{2}{*}{ Monogamy household } & $0.013^{* * *}$ & $0.026^{* * *}$ \\
\hline & $(0.003)$ & $(0.007)$ \\
\hline \multirow[t]{2}{*}{ Spouse with no education } & -0.022 & -0.015 \\
\hline & $(0.025)$ & $(0.026)$ \\
\hline \multirow[t]{2}{*}{ Spouse with primary education } & -0.023 & 0.003 \\
\hline & $(0.024)$ & $(0.029)$ \\
\hline \multirow{2}{*}{ Spouse with secondary education } & -0.026 & -0.016 \\
\hline & $(0.023)$ & $(0.027)$ \\
\hline \multirow[t]{2}{*}{$\mathrm{HH}$ has no education } & -0.001 & $0.055^{* *}$ \\
\hline & $(0.021)$ & $(0.021)$ \\
\hline \multirow[t]{2}{*}{$\mathrm{HH}$ has primary education } & -0.011 & $0.037^{* * *}$ \\
\hline & $(0.020)$ & $(0.013)$ \\
\hline \multirow[t]{2}{*}{ HH has secondary education } & -0.018 & 0.013 \\
\hline & $(0.017)$ & $(0.012)$ \\
\hline \multirow[t]{2}{*}{ Southern Province } & $-0.025^{* * *}$ & -0.018 \\
\hline & $(0.005)$ & $(0.011)$ \\
\hline \multirow[t]{2}{*}{ Western Province } & $-0.019^{* * *}$ & $-0.026^{* *}$ \\
\hline & $(0.006)$ & $(0.012)$ \\
\hline \multirow[t]{2}{*}{ Northern Province } & $0.011^{* *}$ & 0.002 \\
\hline & $(0.005)$ & $(0.017)$ \\
\hline \multirow[t]{2}{*}{ Kigali City } & & $0.227^{* * *}$ \\
\hline & & $(0.013)$ \\
\hline \multirow[t]{2}{*}{ Constant } & $-5.749^{* * *}$ & 4.006 \\
\hline & $(1.437)$ & (3.969) \\
\hline Turning point & 200,138 & $1.30 \mathrm{e}+09$ \\
\hline [95\% confidence interval] & [66753-333522] & {$[-2.84 \mathrm{e}+10$ to $3.10 \mathrm{e}+10]$} \\
\hline Anderson-Rubin test & $21.54^{* * *}$ & $12.33^{* * *}$ \\
\hline Anderson correlation LR test & $225.29 * * *$ & $32.84^{* * *}$ \\
\hline Observations & 11,645 & 2502 \\
\hline
\end{tabular}


Table 3 Estimated W-L model for food consumption: first upper stage (Continued)

\begin{tabular}{lcc}
\hline Explanatory variables & Estimated coefficients & \\
\cline { 2 - 3 } & Rural households & Urban households \\
\hline$R$-squared & 0.254 & 0.539 \\
Expenditure elasticities & $0.76^{* * *}$ & $0.63^{* * *}$ \\
\hline
\end{tabular}

Robust standard errors reported in parentheses are obtained using a clustering approach according to household levels of total expenditures. The Anderson-Rubin test is used to check the joint significance of the endogenous regressors: (Log(total expenditures) and [Log(total expenditures) $]^{2}$ ). The Anderson correlation likelihood ratio (LR) test aims at checking whether the two estimated equations are identified, i.e., that the excluded instruments are relevant. The null hypothesis of the test that the equation is under-identified is highly rejected, i.e., implying that the model is identified. The dependent variable for each equation is household expenditure share of food among rural and urban $\mathrm{HH}$. Asterisks "***", "**", and "**" denote the significance levels at 1, 5, and 10\%, respectively. $\mathrm{HH}$ household head

hypothesis by Kumar et al. (2008) that food expenditure shares would initially rise and later decline as households reach certain levels of food security. This implies that we have positive marginal effects of total food expenditure and negative values for its square. Hence, this is the case where our parametric model estimates indicate significant and strong positive marginal effects of household total food expenditures on shares of cereals, and roots and tubers for rural households.

Furthermore, it is noteworthy to say that demographic characteristics induce important influences on household food demand decisions. Among these variables, we have household size, $\mathrm{HH}$ age, and education of both $\mathrm{HH}$ and spouse. In the case of rural areas, the estimated coefficients of household size are significantly positive for cereals, roots and tubers, and vegetables, while they become negative and not significant for all other food categories. Similar results also occurred in the case of urban households. Other important variables such as education, number of adults in the household, monogamy and $\mathrm{HH}$ age all have various signs and significant levels across food categories and household locations. Therefore, our study results indicate differences in household food consumption patterns, both between and within household location. Altogether,

Table 4 Distribution of expenditure elasticities for all food group categories in Rwanda (computed at the sample mean)

\begin{tabular}{|c|c|c|c|c|}
\hline & \multicolumn{2}{|c|}{ Rural households } & \multicolumn{2}{|c|}{ Urban households } \\
\hline & Conditional & Unconditional & Conditional & Unconditional \\
\hline \multirow[t]{2}{*}{ Cereals } & $0.983^{* * *}$ & $0.751^{* * *}$ & 0.251 & 0.157 \\
\hline & $(0.052)$ & $(0.053)$ & $(0.153)$ & $(0.097)$ \\
\hline \multirow[t]{2}{*}{ Roots and tubers } & $0.816^{* * *}$ & $0.623^{* * *}$ & -0.187 & -0.117 \\
\hline & $(0.065)$ & $(0.057)$ & $(0.192)$ & $(0.121)$ \\
\hline \multirow[t]{2}{*}{ Vegetables } & $0.809^{* * *}$ & $0.618^{* * *}$ & $0.852^{* * *}$ & $0.534^{* * *}$ \\
\hline & $(0.169)$ & $(0.132)$ & $(0.130)$ & $(0.094)$ \\
\hline \multirow[t]{2}{*}{ Meat products } & $1.472^{* * *}$ & $1.125^{* * *}$ & $1.235^{* * *}$ & $0.774^{* * *}$ \\
\hline & $(0.280)$ & $(0.220)$ & $(0.254)$ & $(0.173)$ \\
\hline \multirow[t]{2}{*}{ Beverages } & $1.557^{* * *}$ & $1.190^{* * *}$ & $2.071^{* * *}$ & $1.299^{* * *}$ \\
\hline & $(0.293)$ & $(0.230)$ & $(0.279)$ & $(0.208)$ \\
\hline \multirow[t]{2}{*}{ Other food } & $1.764^{* * *}$ & $1.348^{* * *}$ & $2.156^{* * *}$ & $1.352^{* * *}$ \\
\hline & $(0.130)$ & $(0.117)$ & $(0.212)$ & $(0.177)$ \\
\hline
\end{tabular}

Figures in parentheses are the standard errors of the estimated elasticities. The delta method is used to compute the standard errors of unconditional expenditure elasticities of each food category. The last food category (other food) is a collection of all other various food types consumed by households (some of them include edible oil, spices, sugar products, etc.)

Source: Authors' own computations using EICV4 2013/2014 data 
parametric estimates presented in Additional file 1: Tables S4 and S5 explain household food consumption patterns in Rwanda while accounting for measurement errors in the reported expenditures.

In the end, we compute conditional food consumption elasticities as reported in Table 4. All elasticities are restricted on household locations (food categories in rural and urban households of Rwanda, respectively) and almost all estimated elasticities (with the exception of cereals and roots and tubers for urban households) are statistically significant. We note that for rural households, estimated elasticities for cereals, roots and tubers, vegetables, and meat products are greater than their counterparts obtained for urban households. It is also interesting to point out that meat products, beverages, and the other food group exhibit, in the case of rural households, expenditure elasticities that are higher than one. Regarding urban households, conditional expenditure elasticities for cereals, and roots and tubers are relatively small but not statistically significant. On the other hand, conditional expenditure elasticities for the remaining four food groups range from 0.853 for vegetables to a value of around 2 for beverages (2.071) and the other food group (2.156).

These variations in food expenditure elasticities between rural and urban households can be explained in various ways. First, given that the majority of rural households in SSA, including Rwanda, are smallholder farmers whose livelihoods depend mainly on subsistence farming and limited off-farm income opportunities, expenditure elasticities tend to be high for the food types that they do not produce (IFPRI (International Food Policy Research Institute) 2005). In addition, food consumption in rural areas depends also on other factors such as infrastructure (quality of roads) and distance to markets. Improved infrastructure in transport, for instance, and innovating communications may be important to reduce remoteness (Kilkenny 1998) and hence, for reducing the gap between rural and urban food expenditure elasticities. More specifically in Rwanda, there may be another potential explanation of the differences in expenditure elasticities between rural and urbans households. The country has opted for a Land Consolidation Program (LCP) in 2007 (Del Prete et al. 2019), where each region specializes in producing specific products, depending on the potential in the region. Accordingly, farmers are required to produce in a mono-cropping system to boost farm yields of those crops that were selected by policy-makers in order to be more productive. Although production has significantly increased, this makes it difficult for farmers to buy various food items on local markets since they become more expensive if they are not locally produced, hence making farmers' expenditure elasticities different from those of urban households.

We also compute unconditional consumption elasticities of food using the second stage estimates together with the estimated first stage elasticities. Household food spending behavior is examined through unconditional elasticities of food groups. A well-known economic theory proposition stipulates that, for lower income families food represents an important share of household spending ${ }^{6}$. Findings in Table 4 interestingly reveal that unconditional expenditure elasticities are relatively higher for rural than for urban households for cereals, roots and tubers, and meat products. This is an indication that in Rwanda, rural areas tend to have more poor households than urban areas. That is,

${ }^{6}$ This has been confirmed by the graphical analyses presented in Figs. 2, 3, and 4. 
as total expenditure increases, rural households increase their expenditure on food more proportionally than urban households, especially on starches and cereal products.

In all cases, unconditional expenditure elasticities are positive (except for roots and tubers for urban households). Elasticities obtained for meat products in the case of rural households, beverages and the other food group are high (greater than one) while all the remaining ones are smaller than one, an indication that Rwandan households still spend a large share of their income on food items.

We also derive MM-estimated and IV-tobit models, for robustness checks and expenditure elasticities are provided in Additional file 1: Tables S8 and S9. From an estimation point of view, it shows that MM-estimators tend to give higher income elasticities relative to IV and IV-tobit models. However, the results are not significantly different from each other among the three methods used in this study.

It is noteworthy to mention that, as in other developing countries, various studies on food economics exhibit high food expenditures, especially in rural areas. Previous studies on household consumption behavior such as von Braun et al. (1991) and Moss et al. (2016) indicated that food expenditures in Rwanda are extremely high. They furthermore found that poor households in Rwanda have the largest food expenditure share and the type of food consumed changes with rising income toward more expensive items. Similar results have been reported in the literature by Melo et al. (2015) who found that in Africa, household location plays a significant role in household food expenditure decisions. Specifically, this study indicates that expenditure elasticities are significantly higher for rural relative to urban households and that these differences are mostly found for beverages and meat products. Based on the study results, there is a need for policy-makers to reduce food consumption gaps between rural and urban households.

\section{Conclusion and policy implications}

This study investigates household food demand patterns in Rwanda. This relationship, commonly known as the Engel curve, receives particular attention in food demand and nutritional studies because it is strongly related to food policy. We employ the fourth round Integrated Household Living Conditions Survey of Rwanda (EICV4), conducted within 2013/2014 by NISR. Based on a broad range of empirical specifications, the results reveal a robust and statistically significant quadratic association between food budget shares and total household expenditure. In this respect, we find U-shaped relationships between household food expenditures and the budget shares of vegetables, meat products, beverages, and other food items. This indicates that poor households (with lower incomes) spend less on these food categories as their incomes increase until a certain threshold level and afterwards, food expenditure shares as a proportion of household income start to increase. On the other hand, empirical results show that expenditure shares of cereals, roots and tubers change non-linearly in a concave manner as household food expenditures rise. This implies that at higher incomes, household expenditures on cereals and starches as a proportion of total food expenditures increase initially. After reaching a certain threshold level, those food expenditures as a proportion of total food expenditures start to decline. Furthermore, the discrepancies between rural and urban households in terms of social and economic attributes and household food demand lead us to distinguish the driving factors of food consumption patterns between rural and urban households. To this end, family size, number of adults in the 
household, and education of the household head and spouse are the most contributing factors influencing food demand household decisions.

In addition, nonparametric specifications indicate quadratic shapes of FECs for expenditures on most of the food categories (cereals, starches, vegetables, meat products, beverages, and other food). These findings provide additional evidence for the hypothesis of quadratic FECs in developing countries. More specifically, our analysis provides food consumption elasticities in the Rwandan context. The findings reveal high expenditure elasticities of meat products, beverages and other food items, especially among rural families. The study also gives evidence that there are important differences in food consumption patterns between rural and urban households in Rwanda. That is, as total expenditure increases rural households spend proportionally more on food than urban households, especially on low-value staples such as starches and cereal products. These results reaffirm the findings from earlier literature where households in low-income countries were found to spend a greater portion of their budget on food.

This study contributes further to the understanding of consumption patterns in SSA, more specifically in Rwanda, by deriving the relationships between total household expenditures (income), food expenditures and expenditures on specific food categories. This study, together with earlier literature (Moss et al. 2016; Muhammad et al. 2011; Weatherspoon et al. 2017), confirms high malnutrition prevalence among Rwandan households, mostly in rural areas. In this respect, the study indicates that rural households spend a larger share of their budgets on low-value staples (mostly starches, cereals, roots, and tubers). Our findings are consistent with other studies, for the positive relationship between household income and nutritional outcomes (Abdulai and Aubert 2004), although the effects are small. Therefore, policies aimed at improving economic growth should include measures to increase poor households' incomes to allow them consuming nutritionally diverse diets. The findings from this study may play an important role for policy in terms of food consumption patterns in Rwanda, where rural and urban households have divergent livelihood styles and food demand. Given considerable location differences (in rural and urban areas) among household expenditure elasticities, the study suggests that the effect of food and nutritional policies in the country should be designed differently to accommodate these differences. Further, the LCP, a strategy aimed at boosting food production and optimal land use, needs to be completed with adequate market infrastructure interventions that facilitate market access, hence making it possible for rural and urban households to more easily get access to the food items that they want. Such an approach would enable the country to effectively implement simultaneously the first three goals of the United Nations (UN) Sustainable Development Goals (SDG), where hunger, poverty, and household welfare are the key targets. To this, policy-makers should also continue to be more responsible for food household demands in rural areas to achieve balanced diets. In this respect, locally subsidized micro-food processing industries would be useful for the stability of food prices and household food expenditures.

The study gives a benchmark to analyze household consumption patterns, poverty, and income distribution in Rwanda. Further studies, especially with national household panel data, are needed to analyze location differences in consumption behavior over time. Finally, with the possibility of having price information in household survey data, it is also possible to analyze non-linear income relationships with a full demand system, 
especially with the Quadratic Almost Ideal Demand System (QUAIDS) that simultaneously accounts for quadratic Engel curves and other empirical flexibility conditions.

\section{Supplementary information}

Supplementary information accompanies this paper at https://doi.org/10.1186/s40100-020-00154-4.

\section{Additional file 1.}

\section{Abbreviations}

CFSVA: Comprehensive Food Security and Vulnerability Analysis; EICV: Integrated Household Living Conditions Survey; FAO: The Food and Agricultural Organization; FEC: Food Engel curve; GDP: Gross domestic product; HH: Household head; IV: Instrumental variable; LCP: Land Consolidation Program; LR: Likelihood ratio; MDG: Millennium Development Goals; NISR: National Institute of Statistics for Rwanda; QUAIDS: Quadratic Almost Ideal Demand System; SDG: Sustainable Development Goals; SSA: Sub-Sahara Africa; UK: United Kingdom; UN: United Nations; W-L: WorkingLeser

\section{Acknowledgments}

We gratefully acknowledge the Editor-in-Chief, Liesbeth Dries and the three anonymous reviewers for their constructive suggestions and comments which have improved the work. Financial support from Swedish International Development Agency (SIDA) is greatly appreciated.

\section{Authors' contributions}

The research idea was originally conceived by AN. The authors searched for the existing literature together. They equally contributed together in estimating the empirical models and analyzing the econometric results. They also discussed the results and contributed to the final manuscript. All authors read and approved the final manuscript. Any remaining errors are our own.

Funding

This article has benefited from UR-SWEDEN Program funds, contribution number 51160027.

\section{Availability of data and materials}

The data for the analysis is available online with file name "Data on Food Engel Curves"

\section{Competing interests}

The authors declare that they have no competing of interests.

\section{Author details}

${ }^{1}$ Department of Economics, University of Rwanda, Kigali, Rwanda. ${ }^{2}$ Mistra Center for Sustainable Markets, Stockholm School of Economics, Stockholm, Sweden. ${ }^{3}$ Department of Economics, Södertörn University, Huddinge, Sweden. ${ }^{4}$ Department of Economics, Swedish University of Agricultural Sciences, Uppsala, Sweden. ${ }^{5}$ Department of Agricultural Economics, University of Rwanda, Kigali, Rwanda.

Received: 21 November 2018 Accepted: 18 November 2019

Published online: 03 April 2020

\section{References}

Abdulai A, Aubert D (2004) Nonparametric and parametric analysis of calorie consumption in Tanzania. Food Policy 29(2): $113-129$

Abdulai A, Christian K (2011) Food security policy in developing countries. Chapter 13 in Lusk JL, Roosen J, Shogren JF (eds) The Oxford handbook of the economics of food consumption and politics. Oxford University Press, New York

Almås I (2012) International income inequality: measuring PPP bias by estimating Engel curves for food. Am Econ Rev 102(2): 1093-1117

Banks J, Blundell R, Lewbel A (1997) Quadratic Engel curves and consumer demand. Rev Econ Stat 79(4):527-539

Barrett CB, Reardon T, Webb P (2001) Nonfarm income diversification and household livelihood strategies in rural Africa: concepts, dynamics, and policy implications. Food Policy 26(4):315-331

Behrman JR, Deolalikar AB (1987) Will developing country nutrition improve with income? A case study for rural South India. J Pol Econ 95(3):492-507

Blundell R, Chen X, Kristensen D (2007) Semi-Nonparametric IV estimation of shape-invariant Engel curves. Econometrica 75(6):1613-1669

Blundell R, Duncan A, Pendakur K (1998) Semiparametric estimation and consumer demand. J Appl Econ 13(5):435-461 Boysen O (2016) Food demand characteristics in Uganda: Estimation and policy relevance. South Afr J Econ 84(2):260-293 Cirera X, Masset E (2010) Income distribution trends and future food demand. Philos Trans R Soc B Biol Sci 365:2821-2834 Deaton A (1988) Quality, quantity, and spatial variation of price. Am Econ Rev 78(3):418-430

Deaton A (1997) The analysis of household surveys: a microeconometric approach to development policy. The John Hopkins University Press published for the World Bank, Baltimore

Del Prete D, Ghins L, Magrini E, Pauw K (2019) Land consolidation, specialization and household diets: evidence from Rwanda. Food Policy 83:139-149

Engel J, Kneip A (1996) Recent approaches to estimating Engel curves. J Econ 63(2):187-212 
Fabiosa JF (2011) Globalisation and trends in food consumption. Chapter 23 in Lusk JL, Roosen J, Shogren JF (eds) The Oxford handbook of the economics of food consumption and politics. Oxford University Press, New York

Greene WH (2008) Econometric analysis, 6th edn. Pearson Prentice Hall, Upper Saddle River

Grosh M, Glewwe P (eds) (2000) Designing household survey questionnaires for developing countries. Lessons from 15 years of the Living Standards Measurement Study. Volume 1. The World Bank, Washington, DC

Hasan SA (2016) Engel curves and equivalence scales for Bangladesh. J Asia Pac Econ 21(2):301-315

Hasan SA, Mozumder P (2017) Income and energy use in Bangladesh: A household level analysis. Energy Econ 65:115-126

Hausman JA, Newey WK, Powell JL (1995) Nonlinear errors in variables estimation of some Engel curves. J Econometrics 65(1):205-233

IFPRI (International Food Policy Research Institute) (2005) The future of small farms: proceedings of a research workshop. Jointly organized by International Food Policy Research Institute (IFPRI) / 2020 Vision Initiative Overseas Development Institute (ODI), Imperial College, London

Kedir J, Girma S (2007) Quadratic Engel curves with measurement error: Evidence from a budget survey. Oxford Bull Econ Stat 69(1):123-138

Kilkenny M (1998) Transport costs and rural development. J Reg Sci 38(2):293-312

Kumar TK, Holla J, Guha P (2008) Engel curve method for measuring poverty. Econ Polit Wkly 43(30):115-123

Leser CEV (1963) Forms of Engel functions. Econometrica 31(4):694-703

Lewbel A (1991) The rank of demand systems: theory and nonparametric estimation. Econometrica 59(3):711-730

Lewbel A (2006) Engel curves: entry for the new Palgrave Dictionary of Economics, 2nd edn. Boston College, Boston https:// www2.bc.edu/arthur-lewbel/palengel.pdf

Maxwell D (1999) The political economy of urban food security in Sub-Saharan Africa. World Dev 27(11):1939-1953

Melo P C, Abdul-Salam Y, Roberts D, Gilbert A, Matthews R, Colen L, Mary S, Paloma SGY (2015) Income elasticities of food demand in Africa: a meta-analysis. Technical report. Institute for Prospective and Technological Studies, Joint Research Centre. Sevilla. Spain. doi: 10.279/661336.

Moss CB, Oehmke JF, Lyambabaje A, Schmitz A (2016) Distribution of budget shares for food: an application of quantile regression to food security. Econometrics 4(22). https://doi.org/10.3390/econometrics/4020022

Muhammad A, Seale JL, Meade B, Regmi A (2011) International evidence on food consumption patterns: an update using 2005 International Comparison Program data. USDA-ERS Technical Bulletin No 1929, United States Department of Agriculture - Economic Research Service, Washington DC

National Institute of Statistics of Rwanda (NISR) (2016) Seasonal Agriculture Survey Report, March 2016, National Institute of Statistics of Rwanda, Kigali

National Institute of Statistics of Rwanda (NISR) (2018) Rwanda Poverty Profile Report, 2016/17, November 2018, National Institute of Statistics of Rwanda, Kigali

Pollak R, Wales T (1980) Comparison of the quadratic expenditure system and translog demand systems with alternative specifications of demographic effects. Econometrica 48(3):595-612

Smit W (2016) Urban governance and urban food systems in Africa: examining the linkages. Cities. 58:80-86

UN-Habitat (United Nations Human Settlements Programme) (2014) The state of African cities, Re-imagining sustainable urban transitions. UN-Habitat, Nairobi

von Braun J, De Haen H, Blanken J (1991) Commercialization of agriculture under population pressure: effects on production, consumption, and nutrition in Rwanda. Research report 85. International Food Policy Research Institute, Washington, DC

Weatherspoon DD, Steele-Adjognon M, Niyitanga F, Dushimumuremyi JP, Naseem A (2017) Food expenditure patterns, preferences, policy, and access of Rwandan households. Br Food J 119(6):1202-1215

Working H (1943) Statistical laws of family expenditure. J Am Stat Assoc 38(221):43-56

World Bank (2012) World Bank sees progress against extreme poverty, but flags vulnerabilities, Press release (February 29, 2012). The World Bank, Washington DC http://www.worldbank.org/en/country/rwanda/overview. Accessed 11 Jan 2018

World Bank (2014) Rwanda Economic Update: Unearthing the Subsoil. Press release (August 28, 2014). The World Bank, Washington DC https://www.worldbank.org/en/news/press-release/2014/08/28/the-rwanda-economic-updateunearthing-the-subsoil. Accessed 11 Jan 2018

World Food Program (WFP) (2016) Rwanda 2015-comprehensive food security and vulnerability analysis. United Nations World Food Programme, Rome, p 132 Available at http://www.wfp.org/food-security

Yohai VJ (1987) High breakdown-point and high efficiency robust estimates for regression. Ann Stat 15(2):642-656

You J (2003) Robust estimation of models of Engel curves. Empir Econ 28(1):61-73

\section{Publisher's Note}

Springer Nature remains neutral with regard to jurisdictional claims in published maps and institutional affiliations. 